\title{
Gastric carcinoma in a 13-year-old girl
}

\author{
Fernanda Deutsch, Bruno Zilberstein, Osmar Kenji Yagi, Fabio Crescentini, Claudio Roberto Deutsch, \\ and Joaquim José Gama-Rodrigues
}

Department of Gastrosurgery, Hospital das Clínicas, School of Medicine, University of São Paulo, São Paulo, Brazil

\begin{abstract}
Gastric cancer is uncommon before the fifth decade of life. The appearance of adenocarcinoma in young adults has motivated molecular studies that aimed to identify inherited mutations. Moreover, carcinoma of the stomach in the young adult is sufficiently rare to generate considerable interest in each occurrence of it, especially when it occurs in the gastroesophageal junction. We report a case of gastric carcinoma in a 13-year-old girl, who was referred to our service with weakness, malaise, weight loss, and slight dysphagia. An upper endoscopy with biopsy revealed a gastric Borrmann III tumor, with invasion of the distal esophagus; histopathological analysis revealed a moderately differentiated adenocarcinoma. During staging, she was diagnosed with several metastases, including the lymph nodes, liver, spleen, and ovary. She was referred for radiochemotherapy and died within 4 months. We should consider and investigate the possibility of malignancy even in young patients with persistent symptoms or anemia, in order to diagnose this malignancy at earlier stages.
\end{abstract}

Key words Adenocarcinoma $\cdot$ Stomach $\cdot$ Children

\section{Introduction}

Gastric carcinoma primarily affects patients in the 50-to-70-year age group [1-3]. This tumor is uncommon before the fifth decade of life $[1,4]$. Even though several studies have published reports of cases of adenocarcinoma in young adults [3,5-14], there was evidence of a molecular mutation in some of these patients. This suspicion motivated molecular studies that aimed to identify inherited mutations.

Offprint requests to: F. Deutsch

Rua Albuquerque Lins, 848 apto 161, ZIP 01230-000 São

Paulo SP, Brazil

Received: April 2, 2004 / Accepted: July 22, 2004
The first molecular-based evidence of a hereditary diffuse gastric cancer was the report of inherited mutations in the E-cadherin/CDH1 gene described in Maori kindreds in New Zealand [15]. This finding was confirmed by studies in several other ethnic groups [16,17], and was contested elsewhere [18].

The earliest reported age of a patient with gastric carcinoma was a 10-day-old infant, described in 1877 [19]. McNeer [5], in 1941, reported 501 cases of gastric carcinoma in patients under the age of 31 years. Only $19(3.8 \%)$ were younger than 15 years old. The Mayo Clinic records from 1935 through 1973 revealed no cases of gastric carcinoma among children under the age of 16 years old [13]. A series of 19129 patients of all ages at Memorial Hospital in New York detected no gastric malignancies in children [14]. Thus, carcinoma of the stomach in the young adult is sufficiently uncommon to generate considerable interest in each occurrence of it [9], especially when it occurs in the gastroesophageal junction, as there are few existing reports of cancer in children at this site [7]. We report a case of gastric carcinoma in a 13-year-old girl.

\section{Case report}

A 13-year-old Caucasian girl, previously healthy, presented to our service complaining of a 2-month history of weakness, fatigue, and malaise. She also complained of ongoing slight dysphagia, odynophagia, early satiety, and uncharacteristic right upper quadrant pain during her menstrual period. She denied any other gastrointestinal symptoms, such as nausea, vomiting, epigastric pain, bloating, gastrointestinal bleeding, or alteration of stools. She had had a loss of $11.4 \mathrm{~kg}$ in the 2 -month period before referral (corresponding to $25 \%$ of her previous weight). The patient denied chronic conditions, previous admissions to hospitals, surgery, use of medication or alcoholic beverages, or smoking. There 
was no family history of cancer and her parents and sisters were healthy. At physical examination, she presented signs of anemia and weight loss (body mass index [BMI] 17); no pathological lymph nodes were palpable. Her pulmonary and cardiologic examinations were normal. Her abdomen was flat and painless on palpation, with a slightly enlarged liver, but without palpable masses; there was no ascites or epigastric mass, and intestinal sounds were normal. Rectal examination did not show any abnormalities. There were no clinical features of ataxia telangiectasia.

Laboratory tests revealed microcytic anemia (hemoglobin level, $8.8 \mathrm{~g} / \mathrm{dl}$ ), normal leucocytes, and increased platelets $\left(427000 / \mathrm{mm}^{3}\right)$. Total bilirubin and alkaline phosphatase levels were slightly increased. Albumin level was normal, at the lower limit $[3,8]$. Urinalysis, liver function tests, and clotting studies were all normal. We investigated associated immunodefects, such as hypogammaglobulinemia and common variable immunodefficiency (CVID). However, all levels of immunoglobulins were normal.

An upper endoscopy with biopsy revealed, $35 \mathrm{~cm}$ from the upper incisors, an elevated lesion, friable, located in the posterior and right lateral walls of the esophagus and invading the cardia. From the retrovision of the stomach, extending for $3 \mathrm{~cm}$, an elevated, ulcerated, and infiltrative lesion with active bleeding was seen. The conclusion was that there was a gastric Borrmann III tumor, with invasion of the distal esophagus and active bleeding. The lesion was biopsied and the histopathological diagnosis was a moderately differentiated adenocarcinoma.

For staging purposes, abdominal computed tomography was performed. It revealed parietal infiltration and thickening of the cardia, with extension to the small curvature of the stomach, where the lesion was elevated and lobulated, with a heterogeneous increase after the use of contrast. The liver was slightly augmented, with several hypoatenuated lesions, compatible with metastases, in both lobes, some presenting with central necrosis. There were irregular lesions in the spleen, involving the splenic capsule. There were enlarged lymph nodes at the periaortic level (Fig. 1). The right ovary was enlarged and heterogeneous (Fig. 2). Thoracic computed tomography was also performed, and showed several noncalcified pulmonary lesions, in both lungs, compatible with metastatic lesions (Fig. 3). There were no signs of enlarged mediastinal lymph nodes. Pleural thickening is also found at the right posterior base of the lung.

The patient's nutritional status was impaired due to the obstructive mass. A naso-enteral tube was inserted, guided by endoscopy.

Because the tumor presented at an advanced stage and with active bleeding, the patient was sent for ten radiotherapy sessions, with the purpose of hemostasis. After radiotherapy, the hemoglobin and hematocrit levels were stable and the patient was discharged and sent for outpatient sector follow-up. Palliative chemoradiotherapy was proposed.

The patient died within 4 months of the initial diagnosis.

\section{Discussion}

Tumors of the stomach usually affect patients after the fifth decade of life. It has been estimated that patients younger than 40 years of age represent between $2 \%$ and $8 \%$ of all patients with gastric carcinoma

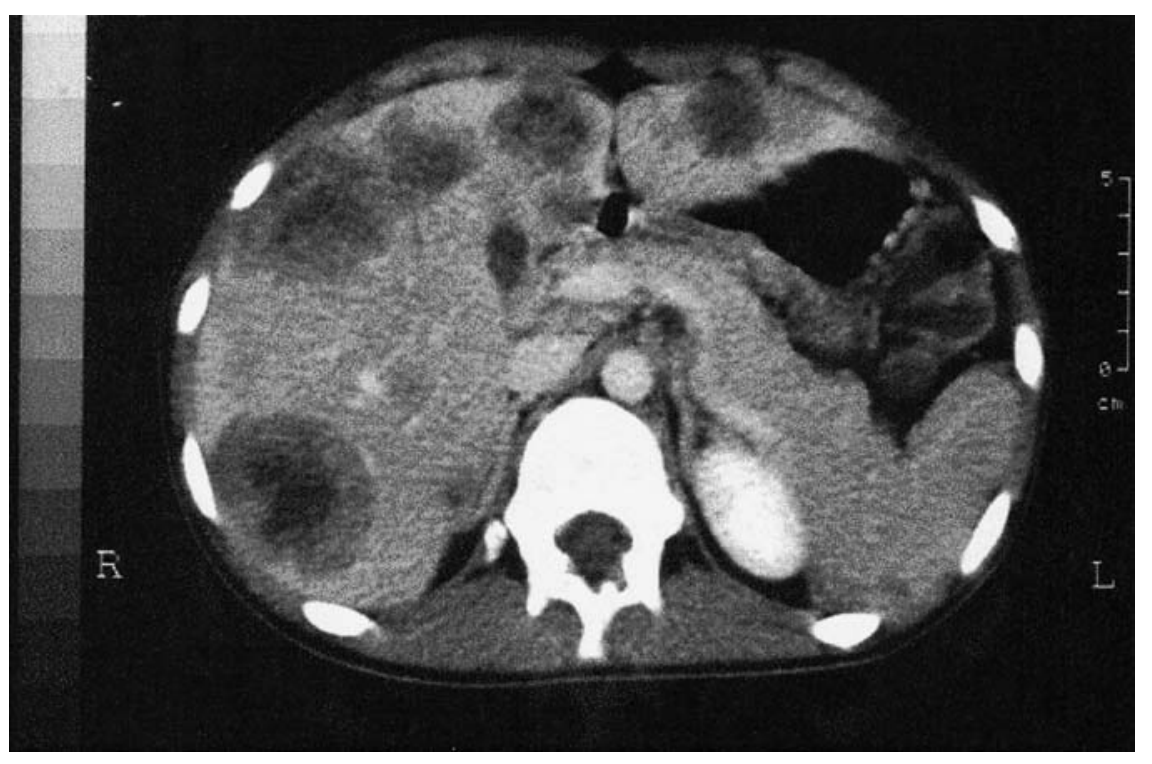

Fig. 1. Computed tomography (CT) shows parietal infiltration and thickening of the cardia, extension to the small curvature of the stomach, enlarged liver, with several metastases, irregular splenic lesions, and enlarged lymph nodes at the periaortic level 


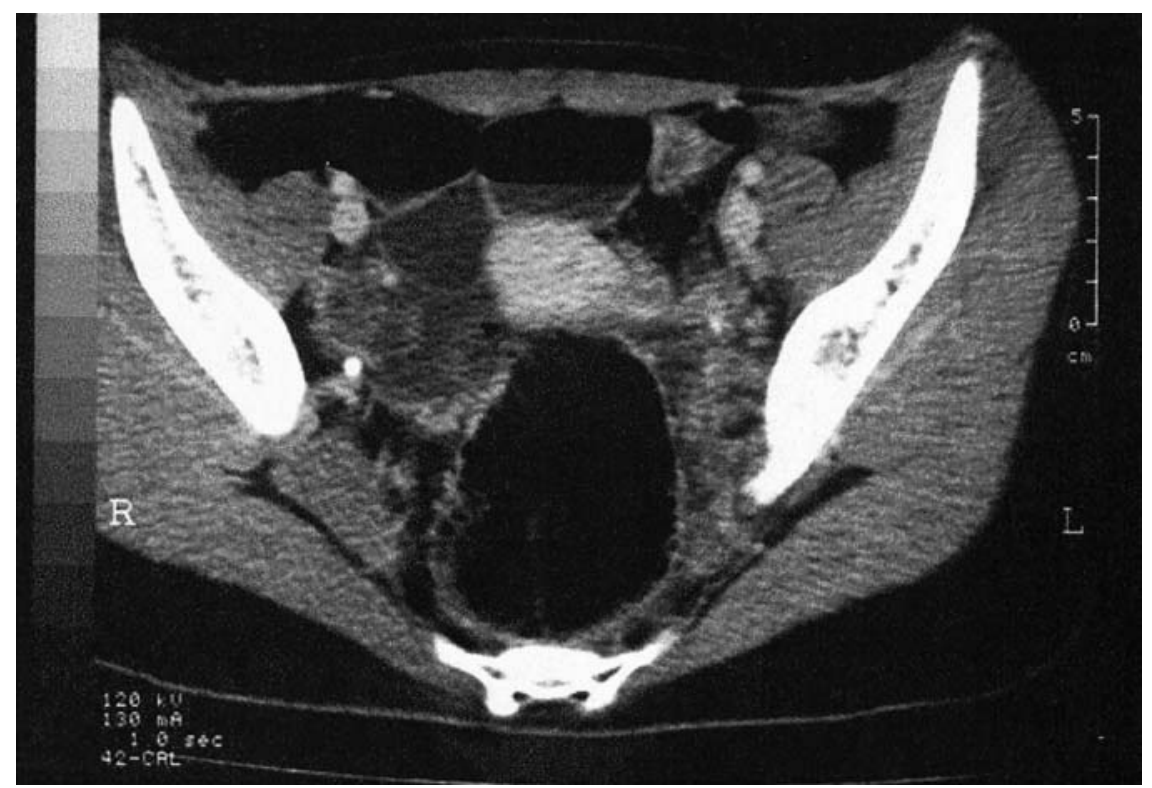

Fig. 2. CT shows enlarged and heterogeneous right ovary

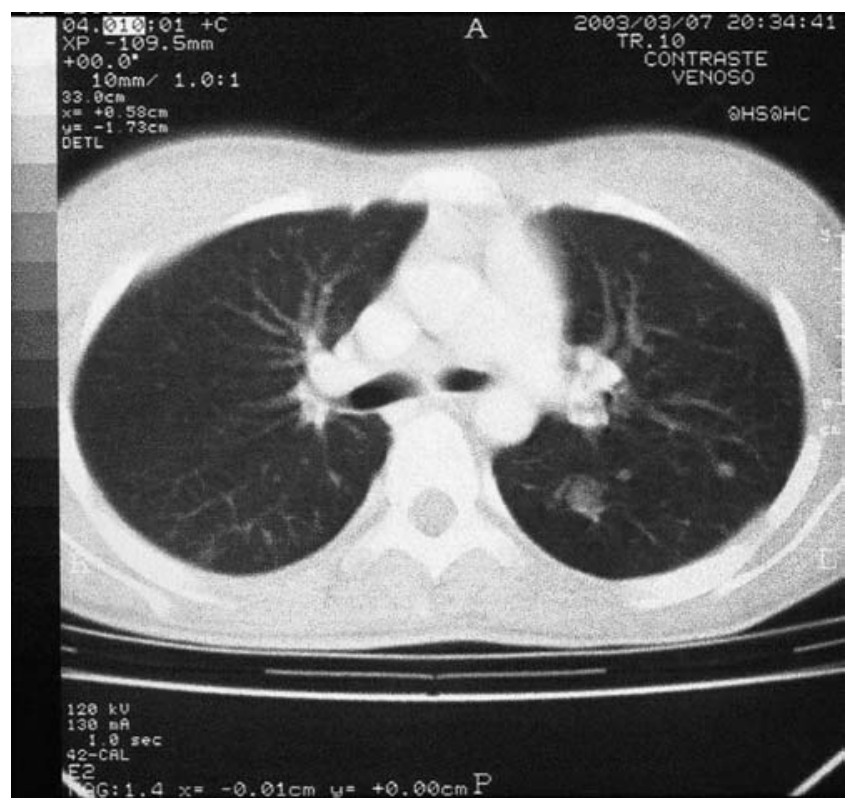

Fig. 3. On thoracic CT several noncalcified pulmonary lesions are seen, in both lungs

$[11,19]$. This concept is so strong that younger patients presenting with characteristic symptoms usually have the correct diagnosis delayed [5], and they are usually empirically treated before an upper endoscopy is performed. In the series of Theuer et al. [1], upper endoscopy was used preoperatively in only $48 \%$ of young patients presenting with gastric cancer, as opposed to $97 \%$ of older patients, even though the symptoms and signs were similar in both groups. Moreover, young patients with gastric carcinoma had a preoperative histologic diagnosis made less frequently (59\% vs $97 \%)$.

In the United States, the annual incidence of all malignant tumors in children is thought to be $9-12 / 100000$ $[7,20]$. It is estimated that cancer of the gastrointestinal tract accounts for less than $5 \%$ of all pediatric neoplasms. Primary malignant tumors of the stomach are exceedingly rare in children, accounting for $0.05 \%$ of gastrointestinal tract tumors $[7,8]$.

Malignant gastric tumors that affect children are mostly lymphomas and soft-tissue sarcomas. Carcinomas are extremely rare $[7,20]$. Since 1960 , about 20 cases have been reported in patients younger than 21 years of age [7], and although there are some other reports in the medical literature, the number of patients is limited. Therefore we are unable to draw significant conclusions in terms of the prognosis, the biological behavior of the tumor [20], the anatomical configuration, the usual locations, and the histology [21].

The female:male ratio is $1: 1$ in patients younger than 21 years, as opposed to $1: 2$ in older patients [2,5]. Tamura and Curtiss [9] found a predominance of young females.

A higher incidence of gastric cancer has been described in relatives of patients who have gastric carcinoma $[9,22,23]$. Such a relation was contested elsewhere [5]. Our patient did not have any family history of gastric cancer.

Although the average age of onset of cancer in families that presented with E-cadherin/CDH1 gene mutation was described as 38 years, a very early onset, at ages as young as 15 years, was also described [24]. Nevertheless, even though our patient presented with a very early onset of cancer, her family history did not fulfill 
the hereditary diffuse gastric cancer clinical criteria. Therefore, her probability of having an E-cadherin/ $\mathrm{CDH} 1$ gene mutation was very low, according to previous studies [25]. However, a blood sample was collected, with consent, and high-molecular genomic DNA was stored in order to check for possible congenital or hereditary disease. Our genomic analysis confirmed that the patient did not have the E-cadherin/CDH1 mutation.

Until recently, heterozygous DNA mismatch repair gene mutations were not described in relation to gastrointestinal tumors. Gallinger et al. [26] studied a family in which two children presented with homozygous germline DNA mismatch repair gene mutations and developed gastrointestinal tumors at very young ages. The 11-year-old boy presented with metastatic duodenal adenocarcinoma that arose in a tubulovillous adenoma, and his 9-year-old sister presented with malignant colon polyps. Their 6 year-old sister has not shown any evidence of malignancy. The family history was not consistent with the criteria for hereditary nonpolyposis colorectal cancer. However, the parents are first-degree cousins, and they remain cancer-free to date. The DNA sequence revealed that all three children had a germline homozygous MLH1 missense smutation.

In young patients, the signs and symptoms do not differ from those in the elderly. The most common symptoms on admission were epigastric pain and vomiting, followed by weight loss, weakness, anorexia, a palpable epigastric mass, and hematemesis $[5,7,9,14]$. For tumors in the gastroesophageal junction the first presenting symptom was dysphagia [27-29]. Physical examination is usually not very conclusive. The most common physical signs are an epigastric mass or tenderness and signs of anemia or cachexia [5]. In other patients, the physical examination may be totally inconclusive [3].

McNeer [5] reported that 275 of the 501 (54.9\%) reviewed patients had distant metastases. Bloss et al. [3] also found that most patients presented with metastases at the time of diagnosis. They also described a high incidence of Krukenberg's tumors, in about $35 \%$ of females with evidence of metastases. Tamura and Curtiss [9] also found common and extensive involvement of the ovaries.

The most common histological type reported in most studies is the mucinous cell type, undifferentiated, with signet-ring cells $[2,8,9,14]$, or poorly differentiated carcinoma [4]. The most common site of origin is the pyloric region $[14,30]$. Other studies demonstrated that most tumors were located in the middle third of the stomach $[4,31]$. Lauren [32] noted that diffuse cancers were more prevalent in younger patients and were associated with a poorer prognosis.
Some of the patients with adenocarcinoma presented with hypogammaglobulinemia or ataxia telangiectasia $[8,14,20,33]$. It has been established that the death rate from malignancy in children with immunodeficiencies is much greater than that in the general age-matched population $[14,20,34,35]$. We checked the serum levels of $\operatorname{IgM}, \operatorname{IgA}, \operatorname{IgG}$, and $\operatorname{IgE}$ in our patient, and they were all normal; also, there were no signs of ataxia telangiectasia.

As for treatment, patients should be offered the same options, regardless of age group, at diagnosis. Surgery is the only treatment that may provide a cure for the disease. Adjuvant therapy is indicated, with complementary purposes, exclusively for advanced inoperable cases.

Prognosis is difficult to estimate. Some authors note that adenocarcinoma is rarely curable in young patients with symptomatic disease, and the prognosis is worse than it is in older patients. Some series have shown that gastric adenocarcinoma in the young is a highly lethal disease, with overall 5-year survival rates ranging from $2.6 \%$ to $20 \%$. These studies emphasize that this tumor is rarely curable in young patients with symptomatic disease [1,3-5,9-11]. Delayed diagnosis is common in young patients in most reported cases, and the delay varies from 1 to 30 months (mean, 2.7 months) $[3,7,21,36]$. Moreover, diffuse-type histology and poorly differentiated lesions are frequent in this age group $[4,32]$. These factors could lead to more advanced cases on presentation and worse prognoses. However, other reports show that the prognosis is not necessarily worse than it is in older patients $[5,10]$, or that it or may even be better [5,37].

In conclusion, gastric carcinoma in children is extremely rare. However, any persistent gastric symptoms or unexplained anemia in children should be carefully examined. We should consider and investigate the possibility of malignancy even in young patients, and the diagnosis should be made at earlier stages, to provide better chances for these patients to undergo curative treatment.

\section{References}

1. Theuer CP, Virgilio C, Keese G, French S, Arnell T, Tolmos J, et al. Gastric adenocarcinoma in patients 40 years of age and younger. Am J Surg 1996;172:473-7.

2. Mitsudomi T, Matsunage T, Wakasugi K, Takenaka M, Kume K, Fujinaga $\mathrm{Y}$, et al. A clinicopathological study of gastric cancer with special reference to age of the patients: an analysis of 1630 cases. World J Surg 1989;13:225-31.

3. Bloss RS, Miller TA, Copeland EM III. Carcinoma of the stomach in the young adult. Surg Gynecol Obstet 1980;150:883-6.

4. Nakamura T, Yao T, Niho Y, Tsuneyoshi M. A clinicopathological study in young patients with gastric carcinoma. J Surg Oncol 1999;71:214-9. 
5. McNeer G. Cancer of the stomach in the young. AJR Am J Roentgenol 1941;45:537-50.

6. Martley PJ, Dent DM, Madden MV, Price SK. Gastric carcinoma in young adults. Ann Surg 1988;207:593-6.

7. McGill TW, Downey EC, Westbrook J, Wade D, de la Garza J. Gastric carcinoma in children. J Pediatr Surg 1993;14:66-7.

8. Nottingham J. Signet-ring carcinoma of stomach in a child. Histopathology 1994;24:490-1.

9. Tamura PY, Curtiss C. Carcinoma of the stomach in the young adult. Cancer 1960;13:379-85.

10. Bellegie NJ, Dahlin DC. Malignant disease of stomach in young adults. Ann Surg 1953;138:7-12.

11. Tso PL, Bringaze WL III, Dauterive AH, Correa P, Cohn I Jr. Gastric carcinoma in the young. Cancer 1987;59:1362-5.

12. Phillips RB. Gastric malignancy in young people. Mayo Clin Proc 1939;14:741-7.

13. Johnston DP, van Heerder J, Lynn HB, Motto JD. Carcinoma of the stomach in a 10-year-old boy. J Pediatr Surg 1975;10:151-2.

14. Siegel SE, Hays DM, Romansky S, Isaacs H. Carcinoma of the stomach in childhood. Cancer 1976;37:1781-4.

15. Guilford P, Hopkins J, Harraway J, McLeod M, McLeod N, Harawira $\mathrm{P}$, et al. E-cadherin germline mutations in familial gastric cancer. Nature 1998;392:402-5.

16. Gayther SA, Gorringe K, Ramus SJ, Huntsman D, Roviello F, Grehan N, et al. Identification of germiline E-cadherin mutations in gastric cancer families of European origin. Cancer Res 1998;58:4086-9.

17. Richards FM, McKee SA, Rajpar MH, Cole TR, Evans DG, Jankowski JA, et al. Germline E-cadherin gene (CDH1) mutations predispose to familial gastric cancer and colorectal cancer. Hum Mol Genet 1999;8:607-10.

18. Iida S, Akiyama Y, Ichikawa W, Yamashita T, Nomizu T, Nihei $\mathrm{Z}$, et al. Infrequent germ-line mutation of the E-cadherin gene in Japanese familial gastric cancer kindreds. Clin Cancer Res 1999;5:1445-7.

19. Wang JY, Hsieh JS, Huang CJ, Huang YS, Huang TJ. Clinicopathologic study of advanced gastric cancer without serosal invasion in young and old patients. J Surg Oncol 1996;63:36-40.

20. Mahour GH, Isaacs H Jr, Chang L. Primary malignant tumors of the stomach in children. J Pediatr Surg 1980;15:603-8.

21. Dixon WL, Fazzari PJ. Carcinoma of the stomach in a child. JAMA 1976;235:2414-5.
22. Graham S, Lilienfeld AM. Genetic studies of gastric cancer in humans; appraisal. Cancer 1958;11:954-8.

23. Maimon SN, Zinninger MM. Familial gastric cancer. Gastroenterology 1953;25:139-42.

24. Caldas C, Carneiro F, Lynch HT. Familial gastric cancer: overview and guidelines for management. J Med Genet 1999;36: 873-80.

25. Oliveira C, Seruca R, Caldas C. Genetic screening for hereditary diffuse gastric cancer. Expert Rev Mol Diagn 2003;3:201-15.

26. Gallinger S, Aronson M, Shayan K, Ratcliffe EM, Gerstle JT, Parkin PC, et al. Gastrointestinal cancers and neurofibromatosis type 1 features in children with a germline homozygous MLH1 mutation. Gastroenterology 2004;126:576-85.

27. Elliot MJ, Ashcroft T. Primary adenocarcinoma of the gastroesophageal junction in childhood. Scand J Thorac Cardiovasc Surg 1983;17:65-6.

28. Hoeffel JC, Nihoul-Fekete C, Schmitt M. Esophageal adenocarcinoma after gastroesophageal reflux in children. J Pediatr 1989; 115:259-61.

29. Adzick NS, Fisher JH, Winter HS, Sandler RH, Hendren WH. Esophageal adenocarcinoma 20 years after esophageal atresia repair. J Pediatr Surg 1985;24:741-4.

30. Mulligan RM, Rewber RR. Histogeneis and biological behavior of gastric carcinoma. Arch Pathol 1954;58:1-25.

31. Mori M, Sugimachi K, Ohiwa T, Okamura T, Tamura S, Inokuchi $\mathrm{K}$. Early gastric carcinoma in Japanese patients under 30 years of age. Br J Surg 1985;72:289-91.

32. Lauren $P$. The two histological main types of gastric carcinoma: diffuse and so-called intestinal-type carcinoma. Acta Pathol Microbiol Scand 1965;64:31-49.

33. Haerer AF, Jackson JF, Evers CG. Ataxia-telangiectasia with gastric adenocarcinoma. JAMA 1969;210:1884-7.

34. Kersey JH, Spector BD, Goos RA. Primary immunodeficiency diseases and cancer: immunodeficiency cancer registry. Int J Cancer 1973;12:333-47.

35. Kersey JH, Gajl-Pecyalska, Nesbit ME. The lymphoid system abnormalities in immunodeficiency and malignancy. J Pediatr 1974;84:789-95.

36. Myers HC. Early diagnosis of carcinoma of the stomach. JAMA 1957;163:159-61.

37. Walters W, Gray HK, Priestley JT, Waugh JM. Malignant lesions of stomach: results of treatment from 1907 through 1938. Proc Staff Meet Mayo Clin 1940;15:625-38. 